Check for updates

Cite this: RSC Adv., 2022, 12, 7433

Received 4th January 2022

Accepted 23rd February 2022

DOI: $10.1039 / \mathrm{d} 2 \mathrm{ra} 00034 \mathrm{~b}$

rsc.li/rsc-advances

\section{Novel magnetic nickel ferrite nanoparticles modified with poly(aniline-co-o-toluidine) for the removal of hazardous 2,4-dichlorophenol pollutant from aqueous solutions $\dagger$}

\begin{abstract}
Mahmoud Abdelwahab Fathy, (D) a Ayman H. Kamel (D)*ab and Saad S. M. Hassan*a
Chlorinated organic and phenolic compounds are still purely studied by many researchers because of their severe damage to the aquatic environment and their carcinogenic effect on many living organisms. Therefore, there is a great interest in removing these environmental pollutants from aqueous mediums by easy and inexpensive methods. Herein, novel nickel ferrite $\left(\mathrm{NiFe}_{2} \mathrm{O}_{4}\right)$ nano composite modified with poly(aniline-co-o-toluidine) (PAOT) is prepared, characterized, and used for the removal of 2,4dichlorophenol (2,4-DCP) as an organic chlorinated environmental pollutant. The morphological properties of the composite are characterized by Fourier transform infrared spectrometry (FTIR), X-ray diffraction (XRD), high-resolution transmission electron microscopy (HR-TEM), and Brunauer-EmmettTeller (BET) methods. The prepared composite is tested for the removal of the hazardous dichlorophenol pollutant from aqueous solutions. Under optimized conditions and with effective control of parameters including, contact time, $\mathrm{pH}$ of the test solution, adsorbent dose, and temperature, over $83 \%$ of the pollutant is adsorbed and removed. The adsorption capacity is $162 \mathrm{mg} \mathrm{g}^{-1}$. Adsorption kinetics, adsorption isotherm and some physicochemical parameters of the reaction are evaluated. The RedlichPeterson isothermal model is the appropriate model for describing the adsorption process. These results indicate that $\mathrm{NiFe}_{2} \mathrm{O}_{4} / \mathrm{PAOT}$ nanocomposites are promising adsorbents for the removal of persistent organic pollutants (e.g., DCP) from aqueous solutions. The results also reveal that modification of $\mathrm{NiFe}_{2} \mathrm{O}_{4}$ particles with poly(aniline-co-o-toluidine) (PAOT) significantly enhances the adsorption capacity of the adsorbent. This is probably due to the electrostatic attraction and non-covalent interactions (e.g. $\pi-\pi$ ) between the aromatic rings in both dichlorophenol and poly(aniline-co-o-toluidine) copolymer. Advantages offered by using $\mathrm{NiFe}_{2} \mathrm{O}_{4}$ /PAOT nanocomposites are the high stability, reasonable efficiency, reusability for at least five adsorption-desorption cycles and the ability to remove the adsorbent from aqueous solutions for reuse using an external magnetic field.
\end{abstract}

\section{Introduction}

Generation of hazardous pollutants by various industrial activities leads to the contamination of the environment, especially the aquatic and soil environments. ${ }^{1}$ For example, chlorophenols and their derivatives, are characterized by strong pungent odor, high toxicity, and carcinogenicity for various organisms, including humans. More seriously, their biodegradability is poor and depends on the number of chlorine atoms per mole and their position in the aromatic ring(s). ${ }^{2,3}$ Due to their antimicrobial properties, they are widely used as a raw

${ }^{a}$ Department of Chemistry, Faculty of Science, Ain Shams University, Cairo 11566, Egypt.E-mail: ahkamel76@sci.asu.edu.eg;ahmohamed@uob.edu.bh

${ }^{b}$ Chemistry Department, College of Science, University of Bahrain, Sakhir 32038, Kingdom of Bahrain

$\dagger$ Electronic supplementary information (ESI) available. See DOI: $10.1039 / \mathrm{d} 2 \mathrm{ra} 00034 \mathrm{~b}$ material in the production of pesticides, herbicides, disinfectants, and preservatives, as well as dyes, phenolic resins, and paper. ${ }^{4,5}$ Their wide use has led to many environmental problems such as soil contamination and pollution of ground and surface water. Consequently, chlorophenols have become one of the leading causes of environmental pollution, ${ }^{6}$ and their removal using less complex methods and low-cost materials has become of paramount importance.

Methods in common use for the removal of chlorinated phenols from aqueous solutions include reverse osmosis, ${ }^{7}$ photo-Fenton degradation, ${ }^{8}$ membrane separation, ${ }^{9}$ sonochemical degradation, ${ }^{10}$ coagulation/flocculation, ${ }^{11}$ and electrochemical degradation. ${ }^{12}$ However, most of these methods require strictly controlled conditions, time-consuming with high operation cost. ${ }^{13}$ To date, adsorption techniques are the most widely method used for contaminants removal, due to their high efficiency, simplicity, low-cost, and regeneration 
ability and reusability of the adsorbent material. ${ }^{\mathbf{1 4 , 1 5}}$ Conventional adsorbents have been used, such as carbon nanotubes, ${ }^{15}$ activated carbon, ${ }^{\mathbf{1 6}}$ oxides, ${ }^{17}$ and microporous polymers, ${ }^{18}$ but these adsorbents have a practical major drawback related to the difficulty of their separation from the treated water. This issue is of a great challenge, especially on the large-scale systems. The difficulty of completely separating of these conventional adsorbents from the treated solution may lead to their accumulation in the environment and thus the creation of another pollutant (secondary pollution source).

Nowadays, this problem has been solved by using magnetic nano-adsorbent materials which have recently attracted research interest for organic pollutants removal from wastewater. Indeed, these nano-magnetic adsorbents have some distinctive characteristics such as high surface area, high absorption capacity, ease of separation by applying an external magnetic field, making them less likely to form a secondary pollutant and thus addressing the defects of conventional adsorbents that have difficulty separating them from contaminated solutions. ${ }^{19-23}$ In addition, there has been great interest in modifying these magnetic nano-adsorbents to increase their efficiency in removing some organic pollutants by using conductive polymers such as polyaniline (PANI) ${ }^{24}$ and polypyrrole (PPy). ${ }^{25}$ These polymer materials provide a high surface area with ductility and malleability, excellent mechanical rigidity, ${ }^{26}$ and unique electrical properties along with unique functional groups (e.g. $-\mathrm{NH}) .{ }^{27}$ Thus, the modification of magnetic nanoparticles with conductive polymers is characterized by its low cost, ease of synthesis, excellent environmental stability, and its ability to prevent agglomeration of magnetic nanomaterials. ${ }^{28}$

In the present work, $\mathrm{NiFe}_{2} \mathrm{O}_{4}$ nanoparticles are prepared, modified by poly(aniline-co- $o$-toluidine) polymer to form $\mathrm{NiFe}_{2} \mathrm{O}_{4} / \mathrm{PAOT}$ nanocomposite. The presence of the $-\mathrm{CH}_{3}$ group attached to the aromatic ring of $o$-toluidine increases its electron density therefore enhances the attachement of the nickel ferrite molecules to poly (aniline-co-o-toluidine) through the formation of a non-covalent bonding via the interaction of the metal complex hydrogen with the electron density in $o$-toluidine ring. Thus, it gives more stability to the prepared nanocomposite. In addition, its ability to increase the possibility of forming a non-covalent $(\pi-\pi)$ bond between the aromatic rings of 2,4-DCP and $o$-toluidine, thus increasing its removal efficiency. The magnetic nanocomposite is characterized and used as adsorbent for the removal of chlorophenol from aqueous solutions. The present magnetic nanocomposite offered some advantages which are low-cost, high adsorption efficiency, ease of preparation, simple regeneration, recycling, and ease of completely separation from the treated solutions.

\section{Experimental}

\subsection{Materials}

2.1.1 Reagents. All reagents were used without further purifications. Ferric chloride hexahydrate $\left(\mathrm{FeCl}_{3} \cdot 6 \mathrm{H}_{2} \mathrm{O}, 97 \%\right)$, nickel chloride hexahydrate $\left(\mathrm{NiCl}_{2} \cdot 6 \mathrm{H}_{2} \mathrm{O}\right)$, ammonium persulfate $\left(\left(\mathrm{NH}_{4}\right)_{2} \mathrm{~S}_{2} \mathrm{O}_{8}\right)$, aniline $\left(\mathrm{C}_{6} \mathrm{H}_{5} \mathrm{NH}_{2}\right)$ and $o$-toluidine $\left(\mathrm{C}_{7} \mathrm{H}_{9} \mathrm{~N}\right)$ were purchased from Sigma-Aldrich (St. Louis, MO, USA). Sodium hydroxide $(\mathrm{NaOH})$ and hydrochloric acid $(\mathrm{HCl})$ were obtained from Merck (Germany). 2,4-Dichlorophenol (2,4-DCP, $\mathrm{C}_{6} \mathrm{H}_{4} \mathrm{Cl}_{2} \mathrm{O}$ ) was obtained from PubChem (St. Rockville Pike, Bethesda, USA). All chemicals were of analytical grade and used as received. Ultrapure water was used for the preparation of all solutions. Stock solutions and all dilute test solutions of 2,4DCP were stored in brown bottles and kept in darkness to prevent degradation.

2.1.2 Synthesis of nano-sized nickel ferrite $\left(\mathrm{NiFe}_{2} \mathrm{O}_{4}\right)$. Aqueous solutions of ferric chloride and nickel chloride in a 1 : 2 molar ratio was mixed with a constant stirring for $30 \mathrm{~min}$ at room temperature $\left(22^{\circ} \mathrm{C} \pm 2{ }^{\circ} \mathrm{C}\right)$. An aqueous $2.0 \mathrm{M} \mathrm{NaOH}$ solution was added dropwise $\left(1.0 \mathrm{~mL} \mathrm{~min}^{-1}\right)$ to the mixture until reaching $\mathrm{pH} 11$. The mixture was then heated to $100{ }^{\circ} \mathrm{C}$ with a constant stirring for $1 \mathrm{~h}$ where a brown precipitate was obtained. The mixture was allowed to stand for ageing overnight. The brown precipitate was washed several times with distilled water until the filtrate's $\mathrm{pH}$ became 7 . The residue was collected and dried at $110{ }^{\circ} \mathrm{C}$ for $6 \mathrm{~h}$. The obtained deep brown powder was calcinated at $600{ }^{\circ} \mathrm{C}$ for $5 \mathrm{~h}$ and kept in a desiccator after being grounded.

2.1.3 Synthesis of $\mathrm{NiFe}_{2} \mathrm{O}_{4} /$ PAOT nanocomposite. Nickel ferrite polymeric nanocomposite was synthesized using the chemical polymerization method. ${ }^{29} \mathrm{~A} 4.5 \mathrm{~g}$ portion of $\mathrm{NiFe}_{2} \mathrm{O}_{4}$ nanoparticles was added to a mixture of $20 \mathrm{~mL}$ chloroform and $30 \mathrm{~mL}$ double-distilled water. The mixture was left in an ultrasonic bath for $1 \mathrm{~h}$ at room temperature $\left(22^{\circ} \mathrm{C} \pm 2{ }^{\circ} \mathrm{C}\right)$. In a parallel step, equimolar amounts of aniline and $o$-toluidine monomers (0.05 mol each) were mixed with $200 \mathrm{~mL}$ of $1.0 \mathrm{M}$ hydrochloric acid at a constant stirring for $30 \mathrm{~min}$. The ferrite and monomers mixtures were mixed under sonication for another $30 \mathrm{~min}$. A $20 \mathrm{~mL}$ aliquot of $0.1 \mathrm{M}$ aqueous ammonium persulfate (APS) solution, as a polymerization initiator, was drop-wise added using a peristaltic pump with a rate of 0.5 $\mathrm{mL} \min ^{-1}$ to the mixture under sonication for $1 \mathrm{~h}$. An intermediate black color was observed in the solution. The reaction mixture was kept overnight. Nickel ferrite modified with poly(aniline-co-o-toluidine) was separated from the reaction mixture using a filter holder set with vacuum pumps and washed several times with double-distilled water followed by methanol. Finally, the obtained black precipitated was dried at $60{ }^{\circ} \mathrm{C}$ and grounded to obtain fine particles.

\subsection{Instruments measurements}

The absorption spectra were recorded with Thermo UV-Visible double-beam spectrophotometer. The infrared spectra were measured with a Pye-Unicam Sp-3-300 Fourier-transform infrared spectrometer (FTIR) equipped with $8101 \mathrm{PC}$ and $\mathrm{KBr}$ technique. X-ray diffraction (XRD) measurements were done with (Bruker AXS-D8, Germany) and CuK $\alpha$ radiation $(\lambda=1.5406$ $\AA$ ) in the $2 \theta$ range from $10{ }^{\circ} \mathrm{C}$ to $70{ }^{\circ} \mathrm{C}$. High-resolution transmission electron microscopy (HR-TEM) was carried out using JEOL-JEM-2100 electron microscope (Osaka, Japan). BrunauerEmmett-Teller (BET) method was performed by adsorption and 
desorption of nitrogen gas at $77 \mathrm{~K}$ using BELSORP MINI X (Osaka, Japan) and automatic surface and pore size analyzer.

\subsection{Investigation of adsorption}

2.3.1 Adsorption techniques. The removal efficiency of the prepared nanocomposites was investigated using the batch equilibrium method. A series of concentrations (10-200 $\mu \mathrm{g}$ $\mathrm{mL}^{-1}$ ) of 2,4-dichlorophenols (2,4-DCP) solution was prepared. Different portions (ranged from 10 to $60 \mathrm{mg}$ ) of the prepared $\mathrm{NiFe}_{2} \mathrm{O}_{4} / \mathrm{PAOT}$ nanocomposite were dispersed in $50 \mathrm{~mL}$ of the test 2,4-DCP aqueous solution at $\mathrm{pH} 4$. The mixtures were left in contact for a period varied from $10 \mathrm{~min}$ to $4 \mathrm{~h}$ at room temperature. The adsorbent particles were separated using a magnet bar. The concentration of 2,4-DCP in the filtrate was spectrophotometrically measured. ${ }^{30}$ A parallel similar series of experiment was made using non modified $\mathrm{NiFe}_{2} \mathrm{O}_{4}$ nano particles. After equilibrium, the removal efficiency and adsorption capacities $\left(\mathrm{mg} \mathrm{g}^{-1}\right)$ of the adsorbent were calculated by the following two eqn (1) and (2): ${ }^{31}$

$$
\begin{gathered}
\text { Removal efficiency }(\%)=\left(\left(C_{\mathrm{o}}-C_{\mathrm{eq}}\right) / C_{\mathrm{o}}\right) \times 100 \\
Q_{\mathrm{eq}}=\left(C_{\mathrm{o}}-C_{\mathrm{eq}}\right) \times V / M
\end{gathered}
$$

where, $C_{\mathrm{o}}$ is the initial concentration of 2,4-DCP $\left(\mu \mathrm{g} \mathrm{mL} \mathrm{m}^{-1}\right), C_{\mathrm{eq}}$ is the concentration of $2,4-\mathrm{DCP}\left(\mu \mathrm{g} \mathrm{mL}^{-1}\right)$ at equilibrium after time $t, V$ is the initial volume of an aqueous 2,4-DCP solution, and $M$ is the mass of adsorbent (g).

2.3.2 Adsorption kinetics. Kinetic studies of 2,4-DCP adsorption on non-modified $\mathrm{NiFe}_{2} \mathrm{O}_{4}$ nanoparticles and modified $\mathrm{NiFe}_{2} \mathrm{O}_{4} / \mathrm{PAOT}$ nanocomposite were investigated and compared. Portions of $40 \mathrm{mg}$ of $\mathrm{NiFe}_{2} \mathrm{O}_{4}$ or $30 \mathrm{mg}$ of $\mathrm{NiFe}_{2} \mathrm{O}_{4} /$ PAOT were added to $50 \mathrm{~mL}$ aliquot of $30 \mu \mathrm{g} \mathrm{mL} \mathrm{m}^{-1}$ of aqueous 2,4-DCP solution at $\mathrm{pH} 4$. The mixture was allowed in contact at different period of times. Pseudo-first order and second-order models were used to analyze the adsorption rate following eqn (3) and (4), respectively. ${ }^{31}$

$$
\begin{gathered}
\ln \left(q_{\mathrm{eq}}-q_{t}\right)=\ln q_{\mathrm{eq}}-k_{1} t \\
t / q_{t}=\left(1 / k_{2} q_{\mathrm{e}}^{2}\right)+\left(t / q_{\mathrm{eq}}\right)
\end{gathered}
$$

where, $q_{\mathrm{eq}}$ and $q_{t}$ are the adsorption capacity $\left(\mathrm{mg} \mathrm{g}^{-1}\right)$ of the adsorbents at equilibrium and at any time; respectively, $t$ is the contact time (min), $k_{1}\left(\mathrm{~min}^{-1}\right)$ and $k_{2}\left(\mathrm{~g} \mathrm{mg}^{-1} \mathrm{~min}^{-1}\right)$ are the rate constants of pseudo first order and second order adsorption, respectively.

2.3.3 Effect of $\mathbf{p H}$. The $\mathrm{pH}$ effect of the aqueous 2,4-DCP test solution on the adsorption of both adsorbents (nano particles and nanocomposite) was investigated. Portions of $40 \mathrm{mg}$ of $\mathrm{NiFe}_{2} \mathrm{O}_{4}$ and $30 \mathrm{mg}$ of $\mathrm{NiFe}_{2} \mathrm{O}_{4} / \mathrm{PAOT}$ were added to $50 \mathrm{~mL}$ of $30 \mu \mathrm{g} \mathrm{mL}{ }^{-1}$ 2,4-DCP aqueous solutions adjusted at $\mathrm{pH}$ $2-11$. The $\mathrm{pH}$ of 2,4-DCP test solutions was adjusted using dilute hydrochloric acid and/or sodium hydroxide.

2.3.4 Adsorption isotherms. $50 \mathrm{~mL}$ aliquots of aqueous 2,4DCP solutions with different concentrations $\left(10-200 \mu \mathrm{g} \mathrm{mL}{ }^{-1}\right)$ and fixed $\mathrm{pH} 4$ were treated with $40 \mathrm{mg}$ of $\mathrm{NiFe}_{2} \mathrm{O}_{4}$ nanoparticles and $30 \mathrm{mg}$ of $\mathrm{NiFe}_{2} \mathrm{O}_{4} / \mathrm{PAOT}$ nanocomposite in separate runs. After a contact time of $2 \mathrm{~h}$ upon using $\mathrm{NiFe}_{2} \mathrm{O}_{4}$ nanoparticles and $4 \mathrm{~h}$ with $\mathrm{NiFe}_{2} \mathrm{O}_{4 /}$ PAOT nanocomposite, the adsorbent particles were separated using a magnet bar. The remaining concentration of 2,4-DCP in the solution was measured using the standard spectrophotometric method. ${ }^{30}$ The experimental data obtained were compared using Langmuir, Freundlich and Redlich-Peterson models. ${ }^{32,33}$ The Langmuir, Freundlich and Redlich-Peterson models were tested by applying eqn (5)-(7); respectively:

$$
\begin{gathered}
q_{\mathrm{eq}}=\left(a_{\mathrm{L}} q_{\mathrm{m}} C_{\mathrm{eq}}\right) /\left(1+b C_{\mathrm{eq}}\right) \\
q_{\mathrm{eq}}=K_{\mathrm{F}} C_{\mathrm{eq}}{ }^{(1 / n)} \\
q_{\mathrm{eq}}=\left(a_{\mathrm{R}} C_{\mathrm{eq}}\right) /\left(1+K_{\mathrm{R}} C_{\mathrm{eq}}{ }^{b}\right)
\end{gathered}
$$

where; $C_{\mathrm{eq}}$ is the 2,4-DCP concentration at equilibrium (mg $\left.\mathrm{L}^{-1}\right), q_{\mathrm{eq}}$ is the equilibrium adsorption capacity of sorbent $\left(\mathrm{mg} \mathrm{g}^{-1}\right), q_{\mathrm{m}}$ is the maximum adsorption capacity of adsorbent $\left(\mathrm{mg} \mathrm{g}^{-1}\right), a_{\mathrm{L}}\left(\mathrm{L} \mathrm{mg}^{-1}\right)$ is the Langmuir constant related to the energy of sorption, $K_{\mathrm{F}}\left(\mathrm{mg}^{(1-1 / n)} \mathrm{L}^{1 / n} \mathrm{~g}^{-1}\right)$ and $n$ are the Freundlich constants related to the adsorption density and adsorption intensity; respectively. $K_{\mathrm{R}}, a_{\mathrm{R}}$ and $b$ are the $R-P$ isotherm constants, where $K_{\mathrm{R}}$ is determined via trials and error to obtain the maximum linear regression value of the isotherm graph.

2.3.5 Reusability of $\mathrm{NiFe}_{2} \mathrm{O}_{4} / \mathrm{PAOT}$ nanocomposite. The usability of $\mathrm{NiFe}_{2} \mathrm{O}_{4} / \mathrm{PAOT}$ nanocomposite adsorbent for repeated removal of dichlorophenol in consecutive cycles was tested. Each cycle was performed as previously mentioned. After each cycle the adsorbent was isolated from the test solution using an external magnet bar. The adsorbent was dipped in $50 \mathrm{~mL}$ of $40 \mathrm{mg} \mathrm{L}^{-1} \mathrm{NaOH}$ for $1 \mathrm{~h}$, then washed with methanol followed by distilled water several times until the filtrate's $\mathrm{pH}$ became around 7 and dried. The regenerated adsorbent was used for sequential adsorption-desorption cycles. The adsorption efficiency and \% 2,4-DCP removal after each cycle was calculated using eqn (2).

\section{Results}

\subsection{Synthesis and characterization of adsorbent}

3.1.1 FTIR spectral measurements. Fig. 1 shows IR spectra of both $\mathrm{NiFe}_{2} \mathrm{O}_{4}$ nanoparticles after calcination and $\mathrm{NiFe}_{2} \mathrm{O}_{4} /$ PAOT nanocomposite after co-polymerization. The IR spectrum of $\mathrm{NiFe}_{2} \mathrm{O}_{4}$ nanoparticles after calcination shows small broad band at $3440 \mathrm{~cm}^{-1}$, attributed to the $\mathrm{O}-\mathrm{H}$ stretching and vibrating modes of adsorbed water during preparation of the $\mathrm{KBr}$ disc. Another two bands appeared in the region of 1632$1382 \mathrm{~cm}^{-1}$ are assigned to asymmetric stretching mode of adsorbed carbonate groups. ${ }^{34}$ The two main bands appear between $585-453 \mathrm{~cm}^{-1}$ are assigned to the intrinsic stretching vibrations of $\mathrm{Fe}-\mathrm{O}$ and $\mathrm{Ni}-\mathrm{O}$ in the spinel structures. ${ }^{35}$ No other bands are detected in the spectrum of the calcinated $\mathrm{NiFe}_{2} \mathrm{O}_{4}$ nano-particles. On the other hand, the IR spectrum of $\mathrm{NiFe}_{2} \mathrm{O}_{4} /$ poly(aniline-co-o-toluidine) composite shows a broad band in 


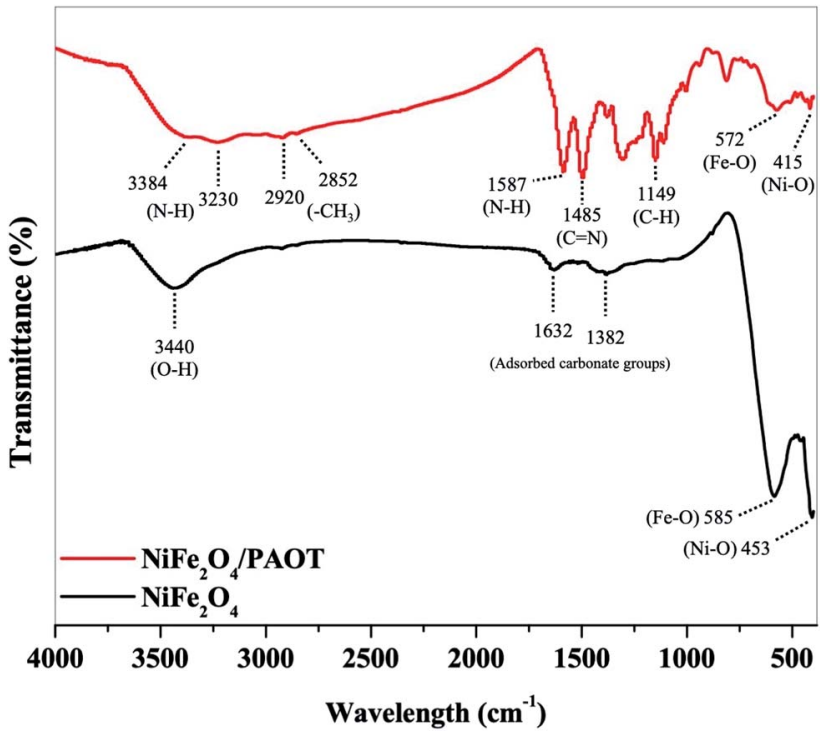

Fig. 1 FTIR spectra of $\mathrm{NiFe}_{2} \mathrm{O}_{4}$ nanoparticles and $\mathrm{NiFe}_{2} \mathrm{O}_{4} / \mathrm{PAOT}$ nanocomposite.

the range $3384-3230 \mathrm{~cm}^{-1}$ assigned to $\mathrm{N}-\mathrm{H}$ stretching. The band is broad due to the presence of hydrogen bonding. ${ }^{36}$ The band appears in the region $2920-2852 \mathrm{~cm}^{-1}$ is due to the stretching vibration of $-\mathrm{CH}_{3}$ group of toluidine moiety. The band displayed in the region $1587-1485 \mathrm{~cm}^{-1}$ is assigned to $\mathrm{N}-\mathrm{H}$ and $\mathrm{C}=\mathrm{N}$ stretching vibrations. Furthermore, other bands in the region 1149-1006 $\mathrm{cm}^{-1}$ are noticed and assigned to $\mathrm{C}-\mathrm{H}$ plane bending: ${ }^{37}$ Finally, two bands are detected between 572 $415 \mathrm{~cm}^{-1}$, corresponding to metal-oxygen vibration bands in the spinel structure's crystal lattice.

3.1.2 X-ray diffraction (XRD) patterns of analysis. The XRD patterns of both $\mathrm{NiFe}_{2} \mathrm{O}_{4}$ nanoparticles and $\mathrm{NiFe}_{2} \mathrm{O}_{4} / \mathrm{PAOT}$ nanocomposite were recorded with a powder X-ray diffractometer (PANalytical, Almelo, Netherlands) using $\mathrm{CuK} \alpha(\lambda=0.154$ $\mathrm{nm}$ ) radiation, and a diffraction angle between $10^{\circ}$ and $70^{\circ}$. The XRD patterns (Fig. 2) indicate, the formation of cubic spinal crystal structure according to the standard of JCPDS (card no. 10-0325), ${ }^{38}$ with no diffraction peaks of other impurities such as $\mathrm{Fe}_{2} \mathrm{O}_{3}$ or $\mathrm{NiO}$ peaks. In case of $\mathrm{NiFe}_{2} \mathrm{O}_{4}$ nanoparticles, there is seven sharp diffraction peaks with $2 \theta$ values at $30.24^{\circ}, 35.48^{\circ}$, $36.94^{\circ}, 43.06^{\circ}, 53.80^{\circ}, 57.20^{\circ}$ and $62.88^{\circ}$ corresponding to the crystal planes (220), (311), (222), (400), (422), (511) and (440), respectively. While in case of the $\mathrm{NiFe}_{2} \mathrm{O}_{4} / \mathrm{PAOT}$ nanocomposite, the XRD pattern is similar to that of $\mathrm{NiFe}_{2} \mathrm{O}_{4}$ nanoparticles with the appearance of an additional broad diffraction band at $2 \theta$ around $15-25^{\circ}$, which is due to the amorphous nature of the copolymer matrix. The intensity of diffraction peaks of $\mathrm{NiFe}_{2} \mathrm{O}_{4} /$ PAOT nanocomposites is appeared at a slightly lower diffraction than that of $\mathrm{NiFe}_{2} \mathrm{O}_{4}$ nanoparticles. This indicates doping of PAOT on the $\mathrm{NiFe}_{2} \mathrm{O}_{4}$ surface without affecting its crystalline structure. The average particles size of $\mathrm{NiFe}_{2} \mathrm{O}_{4}$ and $\mathrm{NiFe}_{2} \mathrm{O}_{4} /$ PAOT was calculated using Scherrer's equation. ${ }^{39}$

$$
D=(K \lambda) /(\beta \cos \theta)
$$

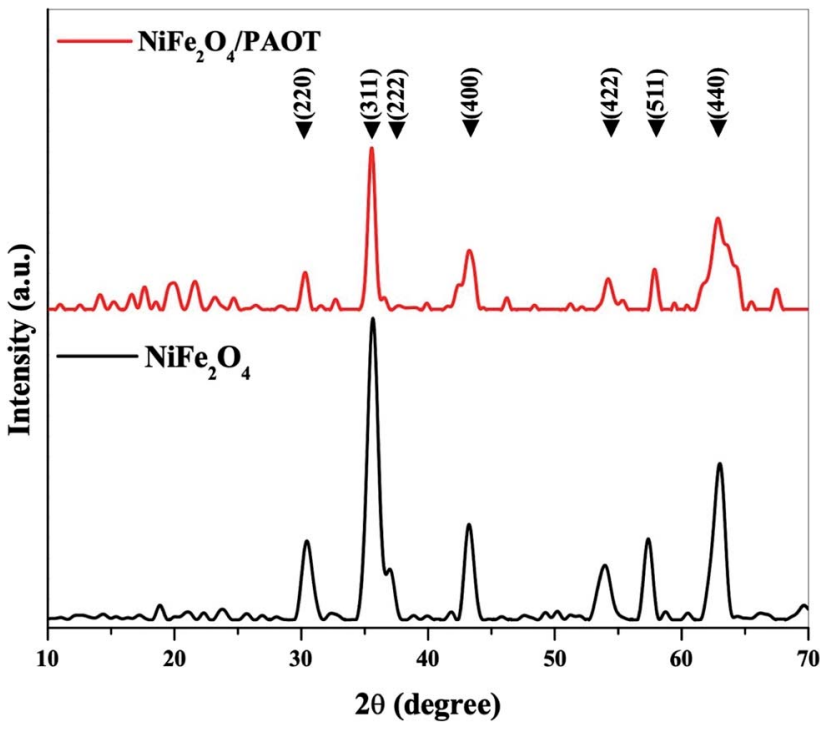

Fig. 2 X-ray diffraction (XRD) patterns of $\mathrm{NiFe}_{2} \mathrm{O}_{4}$ nanoparticles and $\mathrm{NiFe}_{2} \mathrm{O}_{4} /$ PAOT nanocomposite.

where $D$ is the crystalline size, $\lambda$ is the X-ray wavelength $(\mathrm{CuK} \alpha$ radiation and equals to $0.154 \mathrm{~nm}), \theta$ is the Bragg diffraction angle (in radians), and $\beta$ is the full width at half maximum (FWHM) of the XRD peak appearing at the most intense

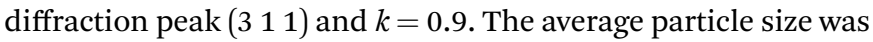
found to be 12.3 and $16.7 \mathrm{~nm}$ for $\mathrm{NiFe}_{2} \mathrm{O}_{4}$ nanoparticles and $\mathrm{NiFe}_{2} \mathrm{O}_{4} /$ PAOT nanocomposites, respectively.

3.1.3 High-resolution transmission electron microscopy (HRTEM). Size and morphology of the prepared $\mathrm{NiFe}_{2} \mathrm{O}_{4}$ nanoparticles (A) and $\mathrm{NiFe}_{2} \mathrm{O}_{4}$ /PAOT nanocomposites (B) were characterized by high-resolution transmission electron microscopy (HR-TEM). As shown in Fig. 3, the HR-TEM image of both compounds (A) and (B) show that the nanoparticles have a uniform, spherical structural morphology with narrow size distribution agglomeration to some extent. The nano size ranges from 12.66-29.87 $\mathrm{nm}$, which is coincided with the XRD results. In Fig. 2(B), The HR-TEM image shows the poly(aniline-co-o-toluidine) layer covering the surface of the $\mathrm{NiFe}_{2} \mathrm{O}_{4}$ nanoparticles.

\subsection{Adsorption properties of magnetic composite}

3.2.1 Nitrogen adsorption/desorption isotherm and pore structure. The nitrogen Brunauer-Emmett-Teller (BET) method was employed to estimate the surface area, pore volume and pore diameter of both the nano and composite materials at 77 $\mathrm{K}$. The $\mathrm{N}_{2}$ adsorption/desorption isotherms on both $\mathrm{NiFe}_{2} \mathrm{O}_{4}(\mathrm{~A})$ and $\mathrm{NiFe}_{2} \mathrm{O}_{4}$ /PAOT (A) (Fig. (S1, I) $\dagger$ ) exhibit a IV type with $\mathrm{H}_{3}$ hysteresis loops. This suggests an adsorbents' mesoporous structure and indicates a monolayer-multilayer adsorption associated with capillary condensation and aggregates of platelike particles (slit-shaped pores) according to IUPAC. ${ }^{\mathbf{4 0}}$

The BET surface area, pore-volume, pore diameter and particles size of $\mathrm{NiFe}_{2} \mathrm{O}_{4}$ nanoparticles and $\mathrm{NiFe}_{2} \mathrm{O}_{4} /$ PAOT nanocomposite data are presented in Table 1 . The size distribution curves for both $\mathrm{NiFe}_{2} \mathrm{O}_{4}$ nanoparticles (A) and $\mathrm{NiFe}_{2} \mathrm{O}_{4} / \mathrm{PAOT}$ nanocomposite (B) (Fig. (S1, II) $\dagger$ ), indicate that the majority of 


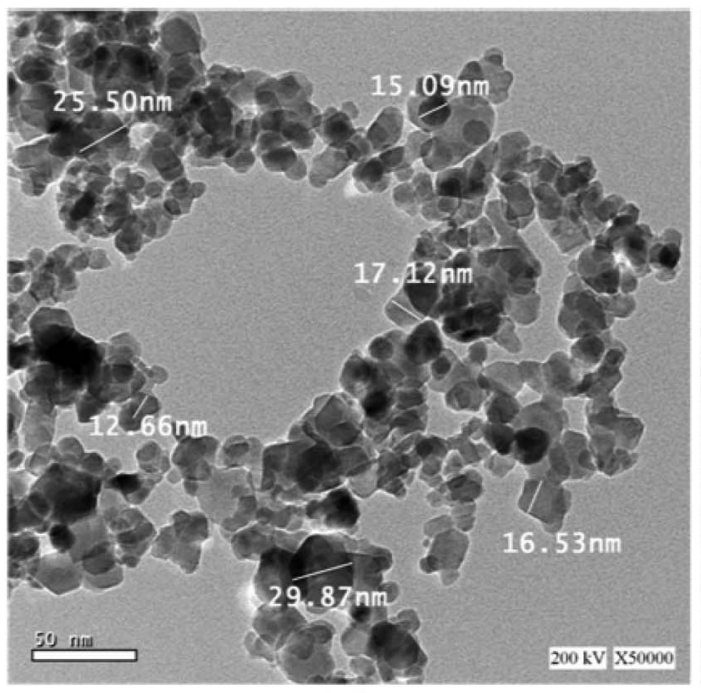

(A)

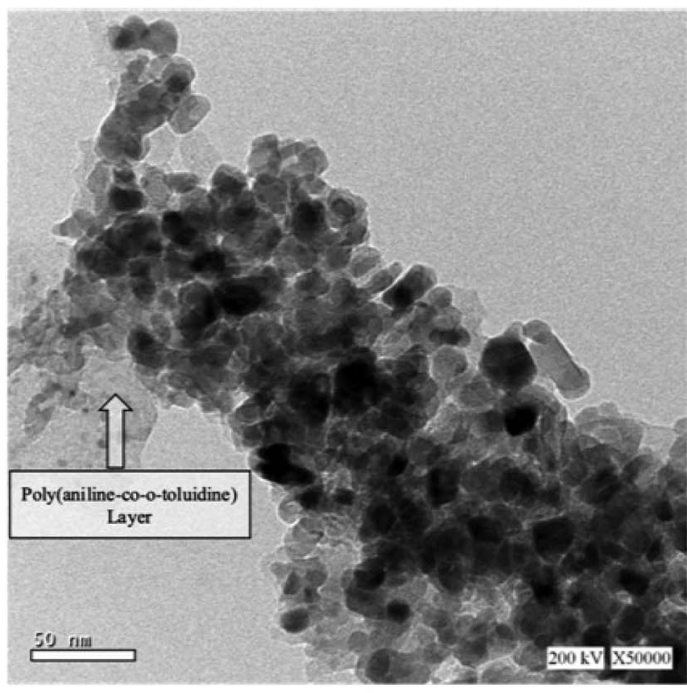

(B)

Fig. 3 High-resolution transmission electron microscopy (HRTEM) images of (A) $\mathrm{NiFe}_{2} \mathrm{O}_{4}$ nanoparticles and (B) $\mathrm{NiFe}_{2} \mathrm{O}_{4} / \mathrm{PAOT}$ nanocomposite.

pores diameter are in the 0.4 to $50 \mathrm{~nm}$ range, characteristic of a mixture of micro and mesoporous materials. ${ }^{41}$ Simultaneously, the average pore diameters are $10.64 \pm 2.80$ and 14.59 $\pm 3.25 \mathrm{~nm}$ for (A) and (B), respectively. The $t$-plot of $\mathrm{NiFe}_{2} \mathrm{O}_{4}$ nanoparticles (A) and $\mathrm{NiFe}_{2} \mathrm{O}_{4} / \mathrm{PAOT}$ nanocomposite (B) (Fig. (S1, III) $\dagger$ ) showed that at $t$-value of $0.9 \mathrm{~nm}$ and $1 \mathrm{~nm}$ for the two materials (A) and (B), the experimental curve deviates from the straight line, indicating that more nitrogen is taken up than the expected for multimolecular adsorption, the capillary condensation has set in at this point. At an average $t$-value of about $1.5 \mathrm{~nm}$ for both samples, the pores responsible for this phenomenon are filled. A new straight line shows the continuation of the multi-layer adsorption on the outer surface and/or side pores' surface. ${ }^{42}$

\subsection{Efficiency of magnetic composite}

3.3.1 Adsorption kinetics. Fig. 4 shows the removal efficiently of 2,4-DCP onto both $\mathrm{NiFe}_{2} \mathrm{O}_{4}$ nanoparticles and $\mathrm{NiFe}_{2} \mathrm{O}_{4} / \mathrm{PAOT}$ nanocomposite as a function of contact time. With $\mathrm{NiFe}_{2} \mathrm{O}_{4}$ nanoparticles, the adsorption of 2,4-DCP increases gradually with time and reaches an equilibrium after $4 \mathrm{~h}$ with a low removal efficiency of around $24 \% \pm 1.3$. However, by using $\mathrm{NiFe}_{2} \mathrm{O}_{4} /$ PAOT nanocomposite, the adsorption of 2,4DCP increases quickly compared with $\mathrm{NiFe}_{2} \mathrm{O}_{4}$ nanoparticles reaching the equilibrium after only $2 \mathrm{~h}$ and the removal efficiency increased to about $83 \% \pm 2.8$.
The adsorption kinetics were studied and used for identifying the adsorption mechanism. As shown in Fig. 5, the experimental kinetics data (Table 2) are fitted with pseudo-first and second-order models. The correlation coefficient $\left(R^{2}\right)$ using pseudo-second-order model is higher than that obtained using pseudo-first-order model, which means that both adsorbents obey pseudo-second-order model. The practical $\left(q_{\mathrm{e}}\right)$ and calculated $\left(q_{\mathrm{e}}^{\exp }\right)$ data for both adsorbents are also calculated.

3.3.2 Effect of adsorbent dose. To optimize the appropriate amount of the adsorbent material for maximum pollutant removal, different quantities of the prepared adsorbents (10-60 $\mathrm{mg}$ ) were used in $50 \mathrm{~mL}$ of 2.4-DCP aqueous solution (30 mg L ${ }^{-1}$ ) at $\mathrm{pH} 4$, and contact time of 2 and $4 \mathrm{~h}$ for $\mathrm{NiFe}_{2} \mathrm{O}_{4}$ nanoparticles and $\mathrm{NiFe}_{2} \mathrm{O}_{4} / \mathrm{PAOT}$ nanocomposites, respectively. As shown in Fig. 6, the removal efficiency increases by increasing the adsorbent dose until reaching its maximum upon using 40 and $30 \mathrm{mg}$ for $\mathrm{NiFe}_{2} \mathrm{O}_{4}$

3.3.3 Effect of $\mathbf{p H}$. The adsorption efficiencies of 2,4-DCP onto both $\mathrm{NiFe}_{2} \mathrm{O}_{4}$ nanoparticles and $\mathrm{NiFe}_{2} \mathrm{O}_{4} / \mathrm{PAOT}$ nanocomposite were tested at various $\mathrm{pH}$ values ranging from 2 to 11 (Fig. 7). In case of $\mathrm{NiFe}_{2} \mathrm{O}_{4} / \mathrm{PAOT}$ nanocomposite, the removal efficiency at $\mathrm{pH}$ lower than 6 is higher than other $\mathrm{pH}$ values. These results demonstrate that the lower $\mathrm{pH}$ values are favorable for the adsorption of 2,4-DCP. Since 2,4-DCP has a $\mathrm{p} K_{\mathrm{a}}$ value of $7.8,{ }^{43}$ it can exist in aqueous solutions in two forms (protonated and deprotonated) depending on the solution's pH.

Table 1 Overall surface characteristic of the proposed adsorbents obtained by Brunauer-Emmett-Teller (BET) method

\begin{tabular}{lllll}
\hline Sample & $\begin{array}{l}\text { Surface area } \\
\left(\mathrm{m}^{2} \mathrm{~g}^{-1}\right)\end{array}$ & $\begin{array}{l}\text { Average pore volume }^{a} \\
\left(\mathrm{~cm}^{3} \mathrm{~g}^{-1}\right)\end{array}$ & $\begin{array}{l}\text { Average pore diameter }^{a} \\
(\mathrm{~nm})\end{array}$ & $\begin{array}{l}\text { Average particle size }^{a} \\
(\mathrm{~nm})\end{array}$ \\
\hline $\mathrm{NiFe}_{2} \mathrm{O}_{4}$ nanoparticles & $61 \pm 1.86$ & $0.240 \pm 2.0 \times 10^{-4}$ & $10.64 \pm 2.80$ & $14.35 \pm 4.04$ \\
$\mathrm{NiFe}_{2} \mathrm{O}_{4} /$ PAOT nanocomposite & $39 \pm 1.43$ & $0.125 \pm 8.2 \times 10^{-3}$ & $14.59 \pm 3.25$ & $17.31 \pm 1.07$
\end{tabular}

${ }^{a} \pm \mathrm{SD}$ ( $n=4$ measurements); where SD is the standard deviation. 

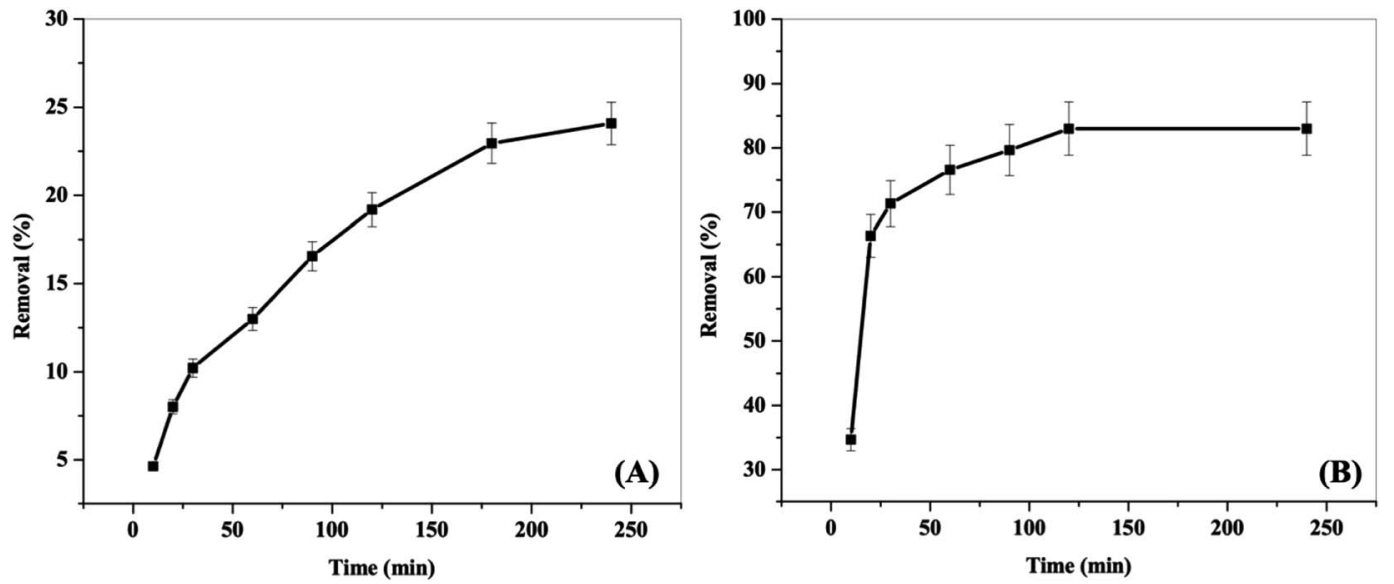

Fig. 4 Effect of contact time on 2,4-DCP removal from aqueous solutions by: (A) $\mathrm{NiFe}_{2} \mathrm{O}_{4}$ nanoparticles and (B) $\mathrm{NiFe}_{2} \mathrm{O}_{4} / \mathrm{PAOT}$ nanocomposite [conditions: initial conc. of 2,4-DCP solution $=30 \mathrm{mg} \mathrm{L}^{-1}$, adsorbent dose $=0.04 \mathrm{~g}$ for ( $\mathrm{A}$ ) and $0.03 \mathrm{~g}$ for $(\mathrm{B}), \mathrm{pH}=4$, volume of solution $=50 \mathrm{~mL}$ ].

\section{(a)}
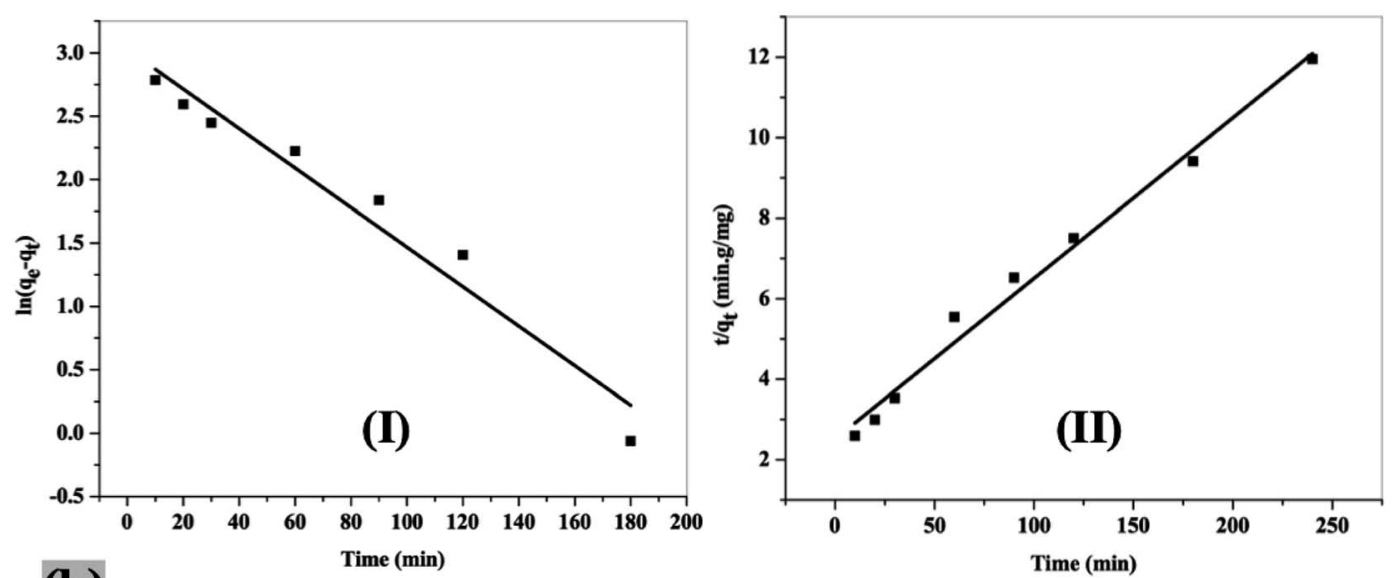

(b)
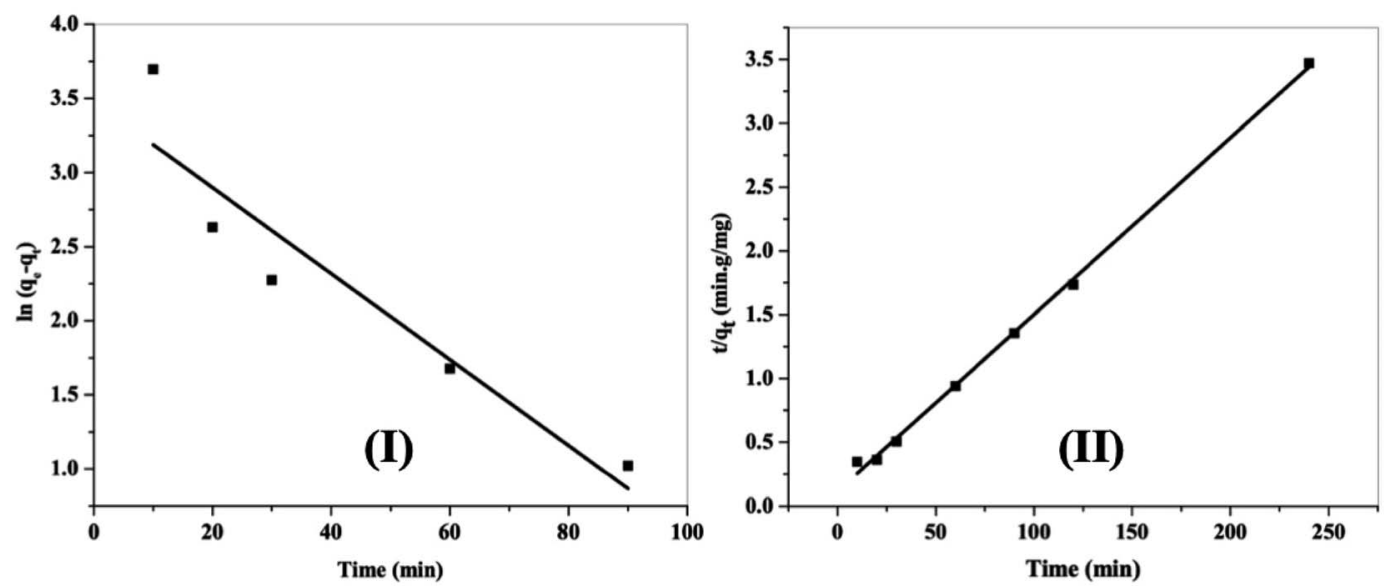

Fig. 5 Kinetics plot of pseudo first order (I) and second order (II) for adsorption of 2,4-DCP onto $\mathrm{NiFe}_{2} \mathrm{O}_{4}$ nanoparticles (a) and $\mathrm{NiFe}_{2} \mathrm{O}_{4} / \mathrm{PAOT}$ nanocomposite (b). 
Table 2 Adsorption kinetics parameters achieved using pseudo first order and second order models

\begin{tabular}{lllllllll}
\hline & \multicolumn{3}{l}{ Pseudo-first order } & & & \multicolumn{2}{l}{ Pseudo-second order } \\
\cline { 2 - 3 } Adsorbent & $k_{1} \times 10^{-2}\left(\mathrm{~min}^{-1}\right)$ & $q_{\mathrm{e} 1}\left(\mathrm{mg} \mathrm{g}^{-1}\right)$ & $R^{2}$ & & $k_{2} \times 10^{-4}\left(\mathrm{~g}(\mathrm{mg} \mathrm{min})^{-1}\right)$ & $q_{\mathrm{e} 2}\left(\mathrm{mg} \mathrm{g}^{-1}\right)$ & $q_{\mathrm{e}}^{\exp }\left(\mathrm{mg} \mathrm{g}^{-1}\right)$ & $R^{2}$ \\
\hline $\mathrm{NiFe}_{2} \mathrm{O}_{4}$ nanoparticles & $1.6 \pm 0.015$ & $20.6 \pm 1.14$ & 0.959 & $6.3 \pm 0.51$ & $25.1 \pm 1.10$ & 20.1 & 0.987 \\
$\mathrm{NiFe}_{2} \mathrm{O}_{4} /$ PAOT nanocomposite & $2.9 \pm 0.060$ & $32.4 \pm 1.36$ & 0.885 & $16.4 \pm 3.20$ & $72.2 \pm 1.32$ & 69.2 & 0.998
\end{tabular}
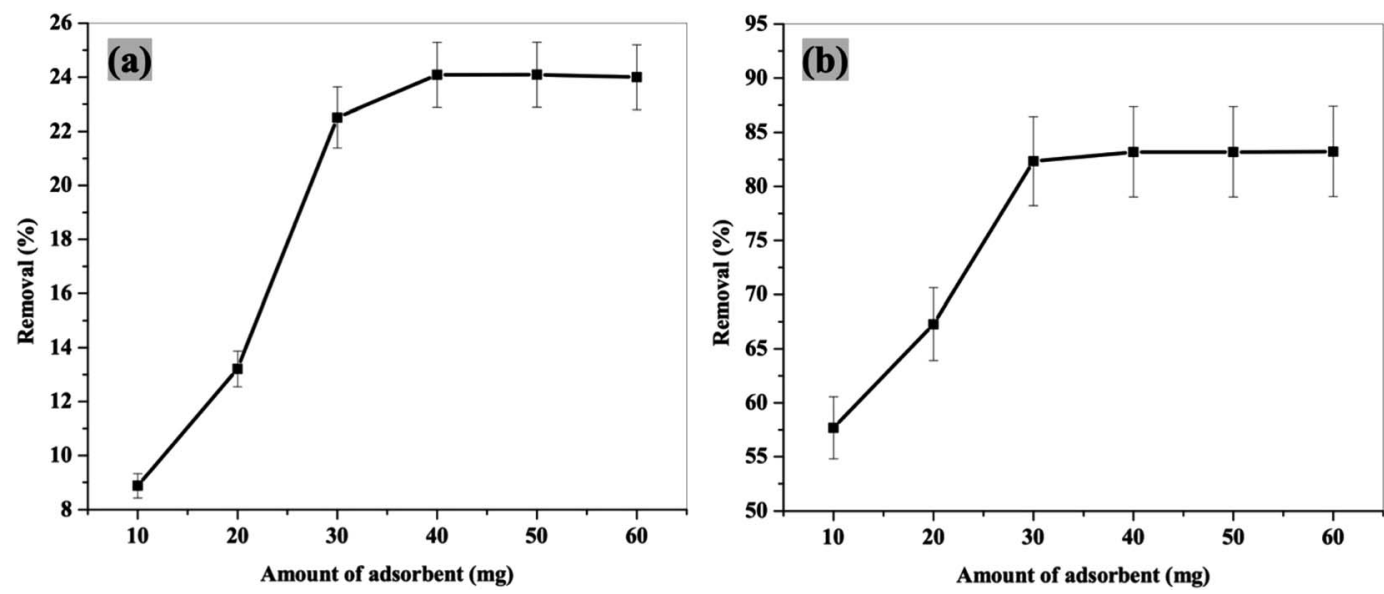

Fig. 6 Effect of adsorbent dose on 2,4-DCP removal from aqueous solutions using $\mathrm{NiFe}_{2} \mathrm{O}_{4}$ nanoparticles (a) and $\mathrm{NiFe} \mathrm{O}_{4} / \mathrm{PAOT}$ nanocomposite (b) [conditions: initial conc. of 2,4-DCP solution $=30 \mathrm{mg} \mathrm{L}^{-1}$, contact time $=4 \mathrm{~h}$ and $2 \mathrm{~h}$ for (a) and (b); respectively, $\mathrm{pH}=4$, volume of solution $=50 \mathrm{~mL}]$.
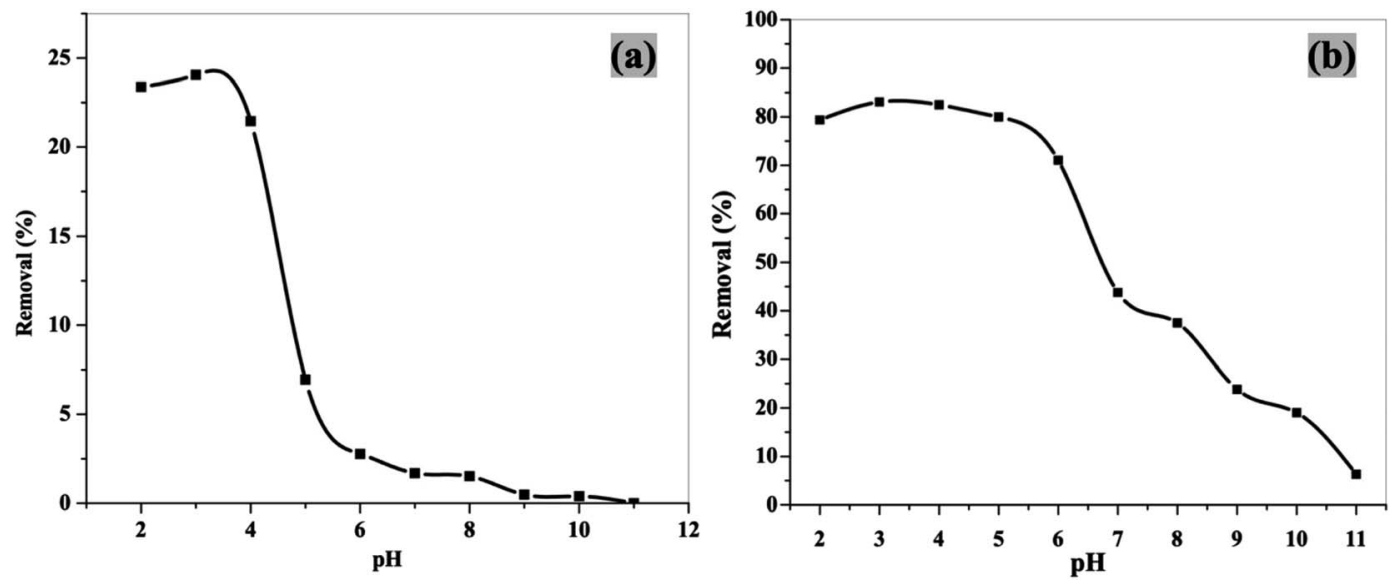

Fig. 7 Effect of $\mathrm{pH}$ on 2,4-DCP removal from aqueous solution using $\mathrm{NiFe}_{2} \mathrm{O}_{4}$ nanoparticles (a) and $\mathrm{NiFe}_{2} \mathrm{O}_{4} / \mathrm{PAOT}$ nanocomposite (b) [conditions: initial conc. of 2,4-DCP solution $=30 \mathrm{mg} \mathrm{L}^{-1}$, volume of solution $=50 \mathrm{~mL}$, contact time $=4 \mathrm{~h}$ and $2 \mathrm{~h}$, and adsorbent dose $=0.04 \mathrm{~g}$ and $0.03 \mathrm{~g}$ for (a) and (b); respectively].

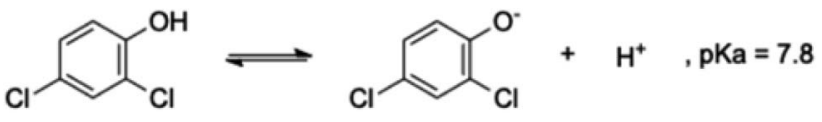

At $\mathrm{pH}<6$, the protonated (nonionized) form is predominant and at $\mathrm{pH}<9$, the deprotonated (dichlorophenate anions) form is predominant, while a mixture of the two forms exists in between. ${ }^{43} \mathrm{~A} \mathrm{pH} 6$ is chosen and used for the removal process by both sorbents.
Zeta potential measurements (Fig. 8) reveal, that the points of zero charge (PZC) for both $\mathrm{NiFe}_{2} \mathrm{O}_{4}$ nanoparticles and $\mathrm{NiFe}_{2} \mathrm{O}_{4}$ /PAOT nanocomposites are 6.4 and 6.6, respectively. At $\mathrm{pH}<6.4$, the oxygen containing group in $\mathrm{NiFe}_{2} \mathrm{O}_{4}$ forms a positively charged aqua complex. At $\mathrm{pH}>6.4$, the oxygen containing group became ionized, forming a negative charge on its surface. In case of $\mathrm{NiFe}_{2} \mathrm{O}_{4} / \mathrm{PAOT}$ nanocomposite, at $\mathrm{pH}<$ 6.6 , the nitrogen atoms of the amine and imine groups present 


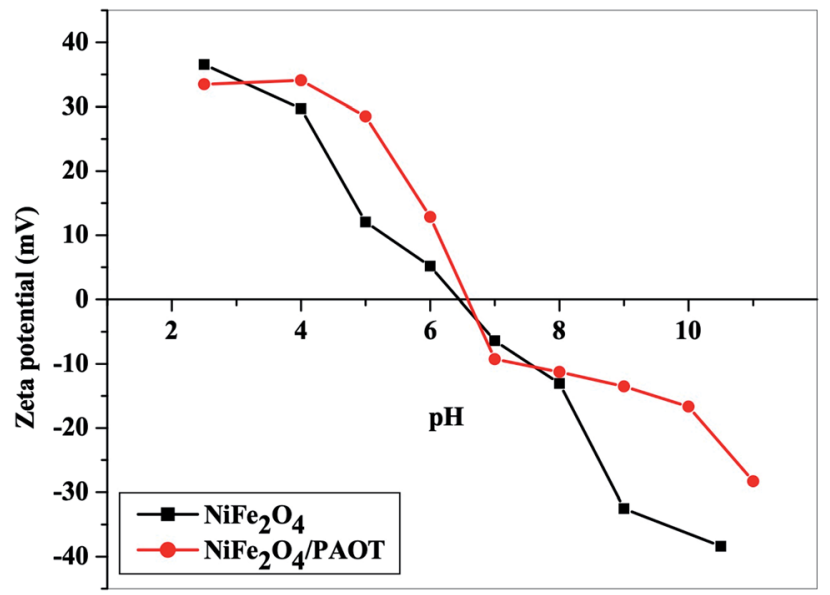

Fig. 8 Plots of zeta potential as a function of $\mathrm{pH}$ for $\mathrm{NiFe}_{2} \mathrm{O}_{4}$ nanoparticles and $\mathrm{NiFe}_{2} \mathrm{O}_{4} /$ PAOT nanocomposite.

in the poly(aniline-co-o-toluidine) composite undergoes protonation leading to the formation of a positive charge on the composite surface. At $\mathrm{pH}>6.6$, the composite surface becomes negatively charged due to the deprotonation of the amine groups. These data explain the high removal efficiency of both adsorbents at low $\mathrm{pH}$ values. The formation of positive charges on the surface of both adsorbents and the nonionized form of 2,4-DCP ( $\left.\mathrm{p} K_{\mathrm{a}}=7.8\right)$, does not cause electrical repulsion. While at high $\mathrm{pH}$ values, both adsorbents' surface became negatively charged, leading to an electrostatic repulsion between the surface of the adsorbent and 2,4-DCP anion, in the test solutions.

3.3.4 Effect of initial concentration of 2,4-DCP solutions. The removal efficiency and adsorption capacity $\left(Q_{\mathrm{e}}\right)$ of $\mathrm{NiFe}_{2} \mathrm{O}_{4}$ nanoparticles and $\mathrm{NiFe}_{2} \mathrm{O}_{4} / \mathrm{PAOT}$ nano composite are tested using different initial concentrations of aqueous 2,4-DCP solutions (ranged from 10 to $200 \mathrm{mg} \mathrm{L}^{-1}$ ). The results are shown in Fig. 9. Using $\mathrm{NiFe}_{2} \mathrm{O}_{4}$ nanoparticles, the removal efficiency remains constant at $23 \%$ over the concentration range 10 to $30 \mathrm{mg} \mathrm{L}^{-1} 2,4-\mathrm{DCP}$, then gradually declined to reach $14.5 \%$ at higher initial adsorbate concentrations (200 $\mathrm{mg} \mathrm{L}^{-1}$ ). By using $\mathrm{NiFe}_{2} \mathrm{O}_{4} /$ PAOT nanocomposite, on the other hand, the removal efficiency remains high and almost constant at $83 \%$ over the initial concentration range of 10 to $50 \mathrm{mg} \mathrm{L}^{-1} 2,4$-DCP. Further increase of 2,4-DCP concentration to $200 \mathrm{mg} \mathrm{L}^{-1}$ causes a slight decrease in the removal efficiency to reach $75 \%$. The adsorption capacity of both adsorbents
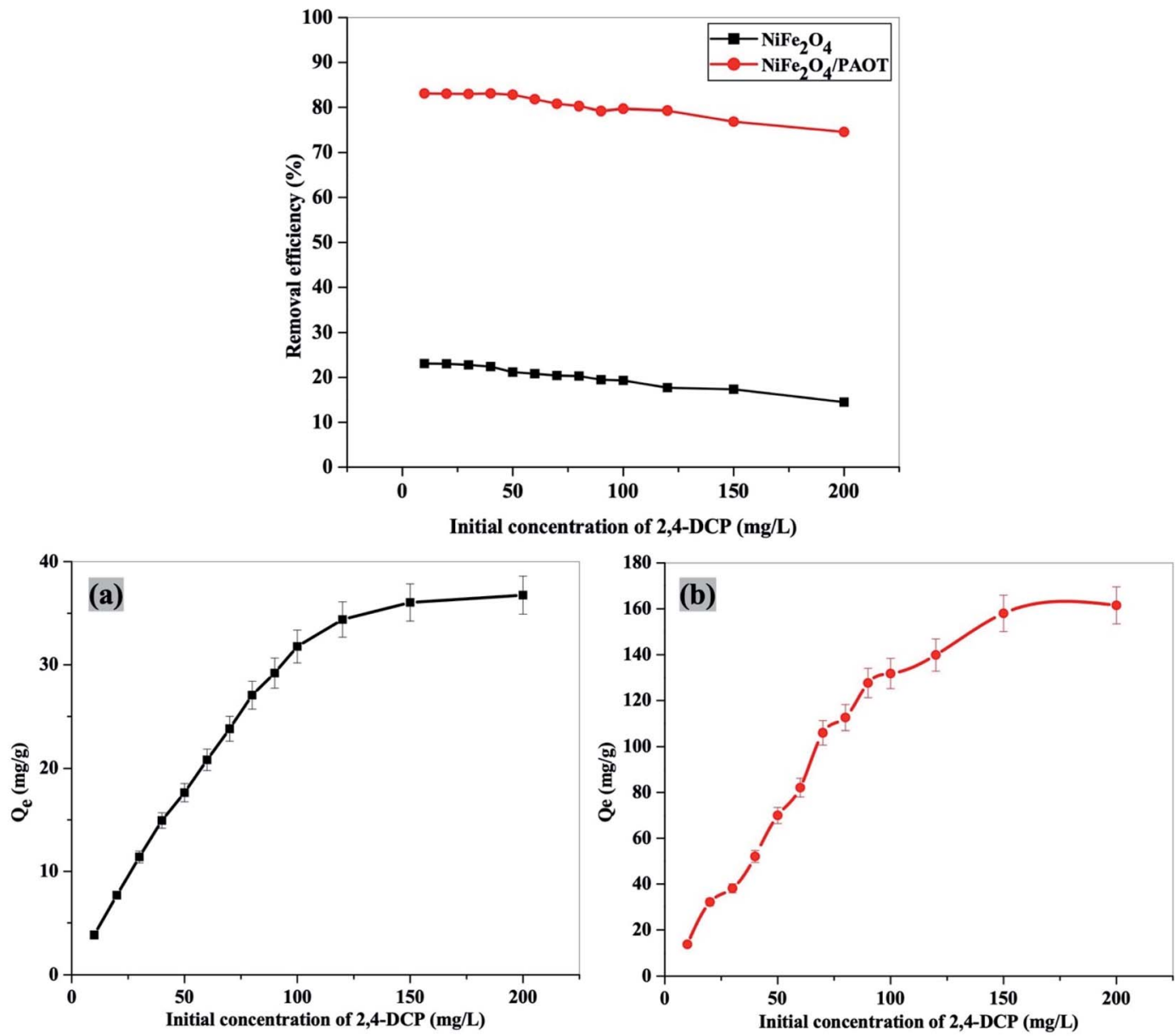

Fig. 9 Effect of initial concentration of 2,4-DCP solution using $\mathrm{NiFe}_{2} \mathrm{O}_{4}$ nanoparticles (a) and $\mathrm{NiFe}_{2} \mathrm{O}_{4} / \mathrm{PAOT}$ nanocomposite (b) [conditions: adsorbent dose $=0.04 \mathrm{~g}$ for (a) and $0.03 \mathrm{~g}$ for (b), $\mathrm{pH}=4$, volume of solution $=50 \mathrm{~mL}$, contact time $=4 \mathrm{~h} \mathrm{for} \mathrm{(a)} \mathrm{and} 2 \mathrm{~h}$ for (b)] . 
increases gradually with increasing the initial concentration of 2,4-DCP until all active sites of each adsorbent are occupied. The maximum adsorption capacity per unit mass $\left(Q_{\mathrm{m}}\right)$ for $\mathrm{NiFe}_{2} \mathrm{O}_{4}$ nano particles and $\mathrm{NiFe}_{2} \mathrm{O}_{4} /$ PAOT nanocomposite are found to be $36 \pm 2 \mathrm{mg} \mathrm{g}^{-1}$ and $162 \pm 3.8 \mathrm{mg} \mathrm{g}^{-1}$, respectively, indicating much higher efficiency of the nanocomposite over the nanoparticle's adsorbate for the removal of 2,4-DCP.
3.3.5 Adsorption isotherms. Langmuir (I), Freundlich (II) and Redlich-Peterson (III) adsorption isotherm models are used to fit the experimental data for $\mathrm{NiFe}_{2} \mathrm{O}_{4}$ nanoparticles and $\mathrm{NiFe}_{2} \mathrm{O}_{4}$ /PAOT nanocomposite as shown in Fig. 10. The isotherm parameters of the three models, and the correlation coefficients $\left(R^{2}\right)$ are illustrated in Table 3. From the Langmuir model, the maximum capacity per unit mass $\left(Q_{\mathrm{m}}\right)$ is $60.0 \pm 4.9$ (a)
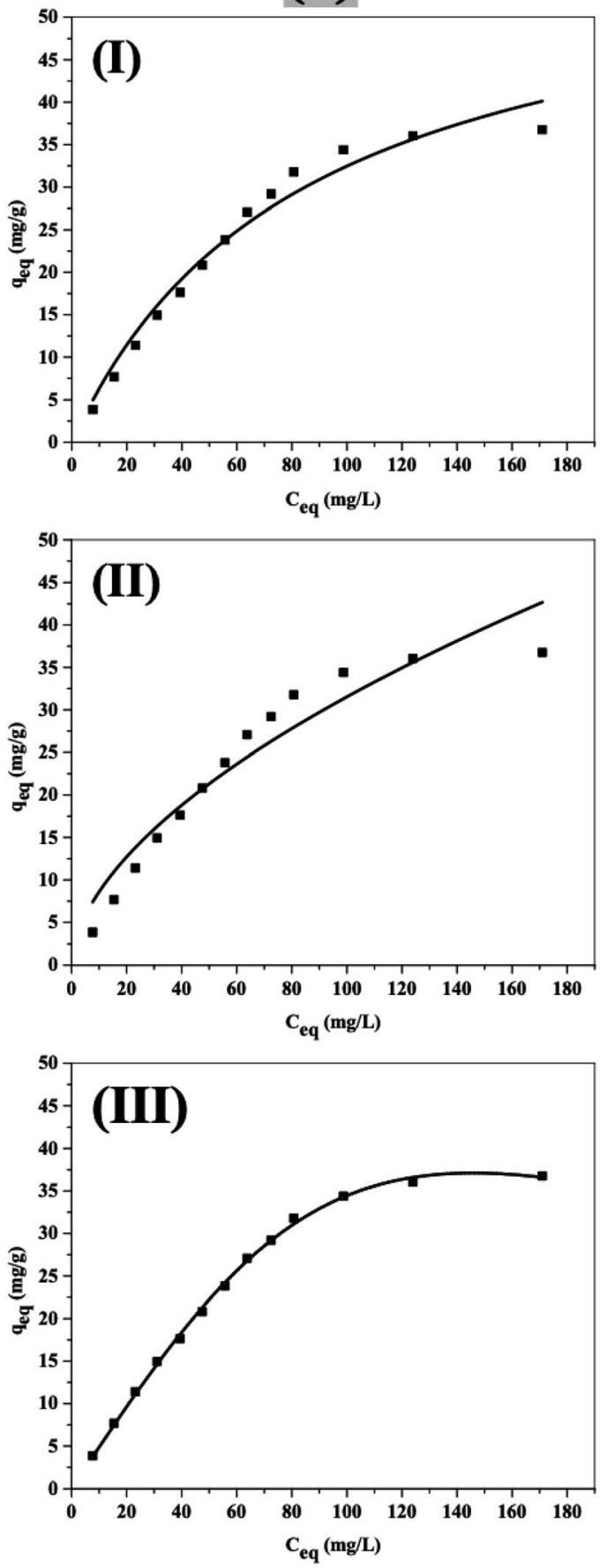

(b)
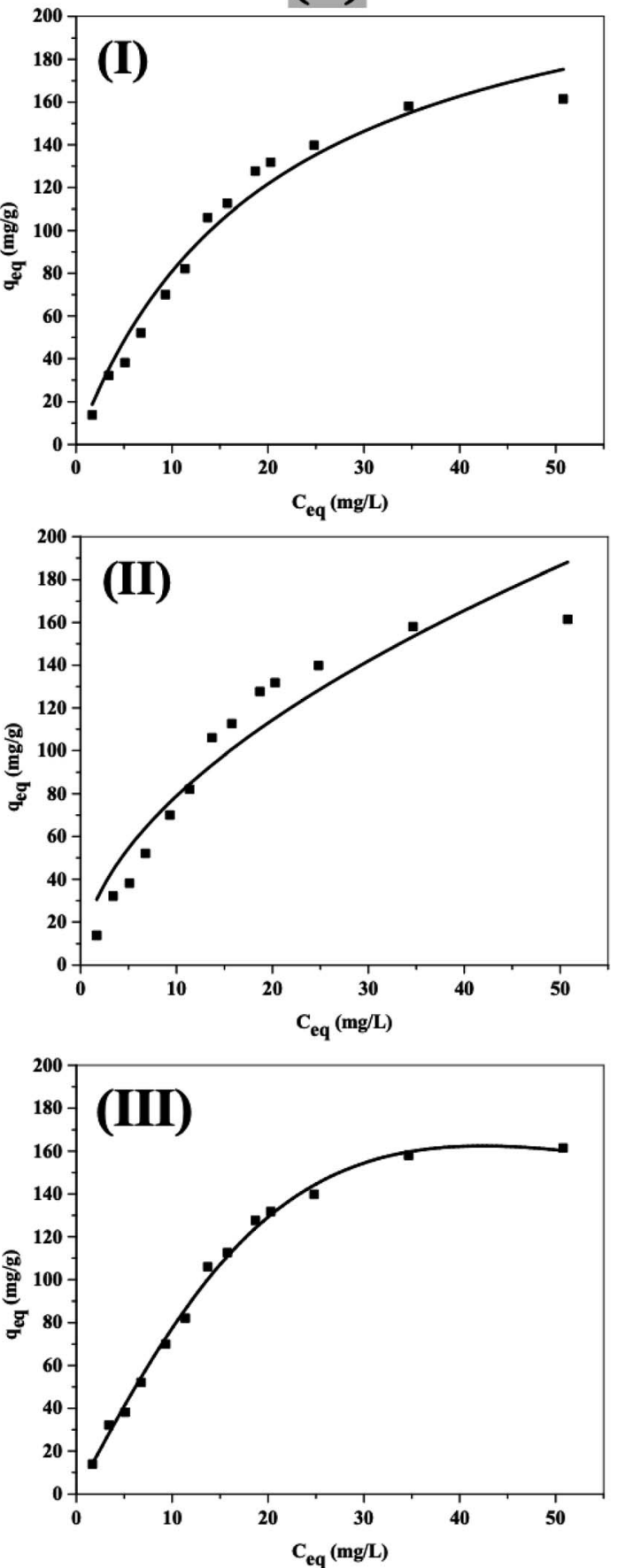

Fig. 10 (I) Langmuir, (II) Freundlich, and (II) Redlich-Peterson isotherms for removal of 2,4-DCP using $\mathrm{NiFe}_{2} \mathrm{O}_{4}$ nanoparticles (a) and NiFe $\mathrm{O}_{4} /$ PAOT nanocomposite (b). 
Table 3 Adsorption isotherm parameters achieved using Langmuir, Freundlich and Redlich-Peterson models

\begin{tabular}{|c|c|c|c|c|c|c|c|c|c|c|}
\hline Adsorbent & \multicolumn{3}{|c|}{ Langmuir model } & \multicolumn{3}{|l|}{ Freundlich model } & \multicolumn{4}{|c|}{ Redlich-Peterson model } \\
\hline $\begin{array}{l}\mathrm{NiFe}_{2} \mathrm{O}_{4} \\
\text { nanoparticles }\end{array}$ & $60.0 \pm 4.9$ & $1.18 \pm 0.185$ & 0.975 & $2.34 \pm 0.62$ & $1.77 \pm 0.04$ & 0.926 & $0.488 \pm 0.0087$ & $2.74 \pm 0.14$ & $2.09 \pm 0.098$ & 0.999 \\
\hline $\begin{array}{l}\mathrm{NiFe}_{2} \mathrm{O}_{4} / \mathrm{PAOT} \\
\text { nanocomposite }\end{array}$ & $245.8 \pm 19.3$ & $4.91 \pm 0.783$ & 0.972 & $23.06 \pm 4.48$ & $1.87 \pm 0.05$ & 0.911 & $8.384 \pm 0.3280$ & $119.72 \pm 7.53$ & $1.84 \pm 0.151$ & 0.998 \\
\hline
\end{tabular}

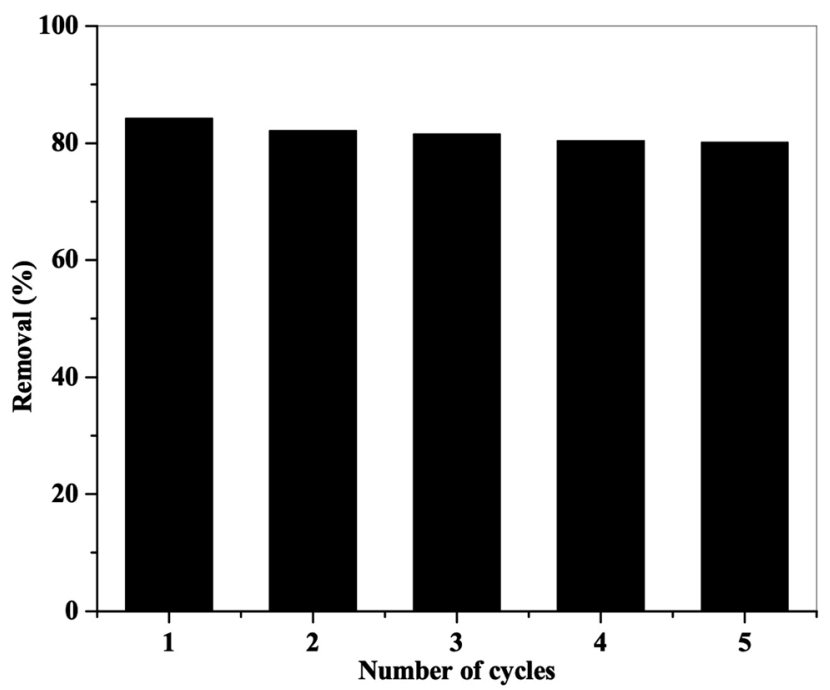

Fig. 11 2,4-DCP adsorption-desorption cycles on $\mathrm{NiFe}_{2} \mathrm{O}_{4} / \mathrm{PAOT}$ nanocomposite.

and $245.8 \pm 19.3 \mathrm{mg} \mathrm{g}^{-1}$ for $\mathrm{NiFe}_{2} \mathrm{O}_{4}$ nanoparticles and $\mathrm{NiFe}_{2} \mathrm{O}_{4} / \mathrm{PAOT}$ nanocomposite, respectively. According to the regression correlation coefficients $\left(R^{2}\right)$, it is observed that both adsorbents obey Redlich-Peterson model as the $R^{2}$ of both are close to 1 and higher than that obtained using Langmuir and Freundlich models. This finding suggests that the adsorption mechanism is a mix of Langmuir and Freundlich isotherms and does not follow the ideal monolayer adsorption process. ${ }^{44}$

3.3.6 Desorption and regeneration of $\mathrm{NiFe}_{2} \mathrm{O}_{4} / \mathrm{PAOT}$ nanocomposite. Regeneration of $\mathrm{NiFe}_{2} \mathrm{O}_{4} / \mathrm{PAOT}$ nanocomposite for re-using in multiple adsorption cycles was investigated (Fig. 11). After the first cycle, the adsorbent was collected, dipped in dilute sodium hydroxide solution, followed by washing with methanol and water and reused in the next adsorption cycle. This process was repeated several times until the \% removal of dichlorophenol efficiency decreased. The results show that after five adsorption-desorption cycles, the removal efficiency for 2,4-DCP slightly declined from 83 to $80 \%$.

3.3.7 Adsorption mechanism. There are some possible explanations for the mechanism of 2,4-DCP adsorption on the proposed adsorbents (Fig. 12 and 13). With $\mathrm{NiFe}_{2} \mathrm{O}_{4}$ nanoparticles at low $\mathrm{pH}$ values, the aqua metal complex (i.e., $\mathrm{M}-$ $\mathrm{OH}_{2}^{+}$) is formed. The hydrogen bonds formed between $-\mathrm{Cl}$ or $-\mathrm{OH}$ present in the 2,4-DCP aromatic ring and the hydrogen atom present in the aqua nickel ferrite complex facilitate the removal of the adsorbate. Alternatively, the formation of a weak non-covalent $\left(\mathrm{M}-\mathrm{OH}_{2}{ }^{+} \cdots \pi\right)$ bonding between the hydrogen atom in the aqua complex and the electron density present on the 2,4-DCP aromatic ring ${ }^{45}$ enhances adsorbate removal.

With $\mathrm{NiFe}_{2} \mathrm{O}_{4} /$ PAOT nanocomposite, the nickel ferrite molecules attached to the poly(aniline-co-o-toluidine) through the formation of a hydrogen bonding between the hydrogen of the aqua metal complex and the nitrogen atom of the copolymer. Other possibility is the formation of noncovalent bonding $\left(\mathrm{M}-\mathrm{OH}_{2}{ }^{+} \cdots \pi\right)$ by interaction of the metal complex hydrogen and the electron density of aromatic ring of $o$-toluidine in the copolymer which enhanced by the inductive effect of toluidine $-\mathrm{CH}_{3}$ group. Other possible mechanism and route of reaction involves the adsorption of the 2,4-DCP on the surface of $\mathrm{NiFe}_{2} \mathrm{O}_{4} / \mathrm{PAOT}$ nanocomposite and formation of a hydrogen bonding between $-\mathrm{Cl},-\mathrm{OH}$ and $-\mathrm{H}$ of 2,4DCP with $-\mathrm{NH}_{2}$ and $-\mathrm{N}=,-\mathrm{NH}-$ and $=\mathrm{NH}-$ groups of the copolymer. Formation of non-covalent bonding $(\mathrm{H}-\pi)$ between hydrogen atom (-OH) of 2,4-DCP and the electron density of the aromatic rings of the copolymer is another route of interaction.

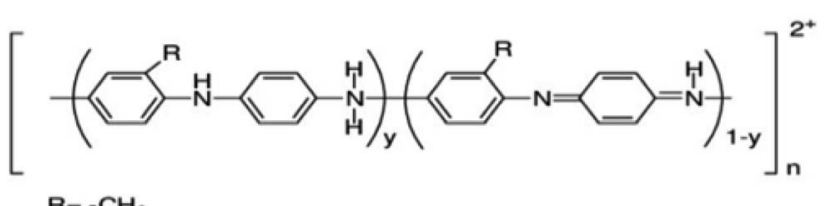

Other possible source of reaction involves the formation of non-covalent $(\pi-\pi)$ interaction due to the dispersion forces between $\pi$ electrons in 2,4-DCP aromatic ring and $\pi$ electrons in $o$-toluidine (electro-rich) aromatic ring exist in the copolymer. The different and various possible modes of adsorbate/ adsorbent interactions descried above (vide supra) support and confirm the high efficiency and superiority of $\mathrm{NiFe}_{2} \mathrm{O}_{4} / \mathrm{PAOT}$ nanocomposite over $\mathrm{NiFe}_{2} \mathrm{O}_{4}$ nanoparticles for the removal of 2,4-DCP from aqueous solutions.

Table 4 presents the main characteristics of some previously suggested adsorbents for removal of dichlorophenol from aqueous solutions. The proposed $\mathrm{NiFe}_{2} \mathrm{O}_{4} /$ PAOT nanocomposite adsorbent offers the advantages of relative short contact time, high adsorption capacity, high removal efficiency, low cost, ease of preparation, regeneration, recycling, and reuse. 


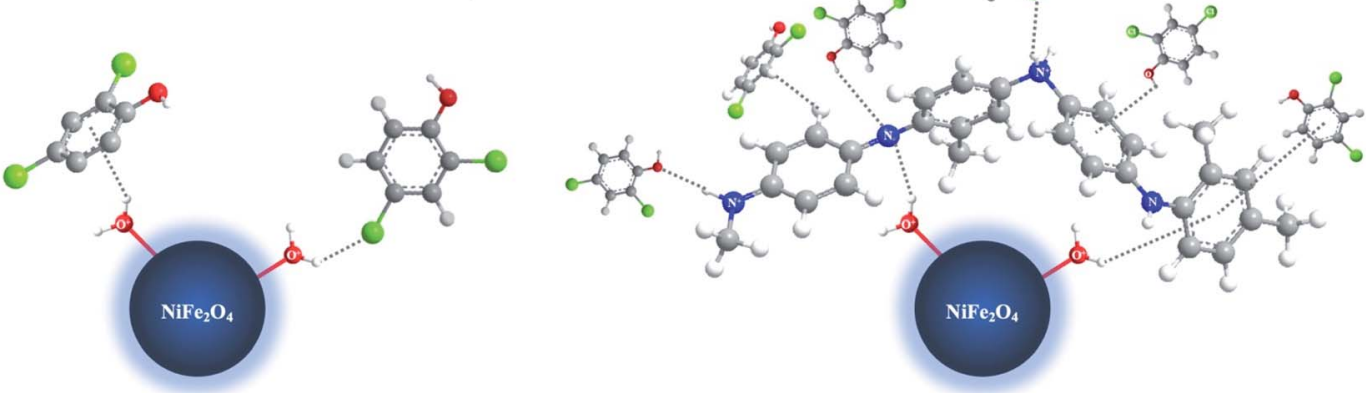

Fig. 12 3D-Simulation of the adsorption mechanism of 2,4-DCP on $\mathrm{NiFe}_{2} \mathrm{O}_{4}$ nanoparticles and $\mathrm{NiFe}_{2} \mathrm{O}_{4} / \mathrm{PAOT}$ nanocomposite.
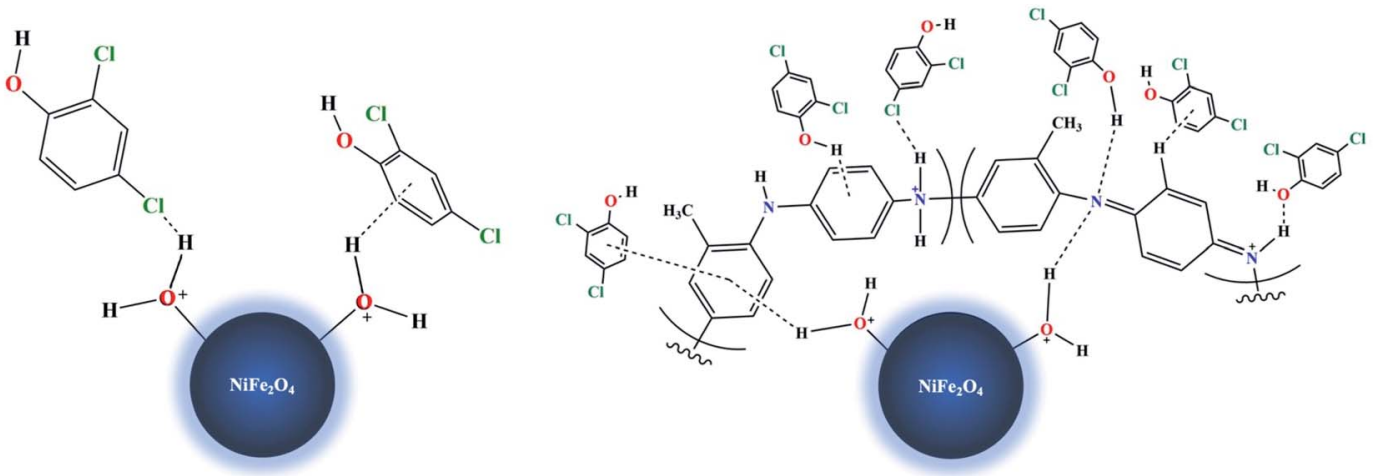

Fig. 13 Schematic 2D-Simulation for the adsorption mechanism of 2,4-DCP on $\mathrm{NiFe}_{2} \mathrm{O}_{4}$ nanoparticles and $\mathrm{NiFe}_{2} \mathrm{O}_{4} / \mathrm{PAOT}$ nanocomposite.

Table 4 Performance characteristics of some adsorbents used for the removal of 2,4-dichlorophenol

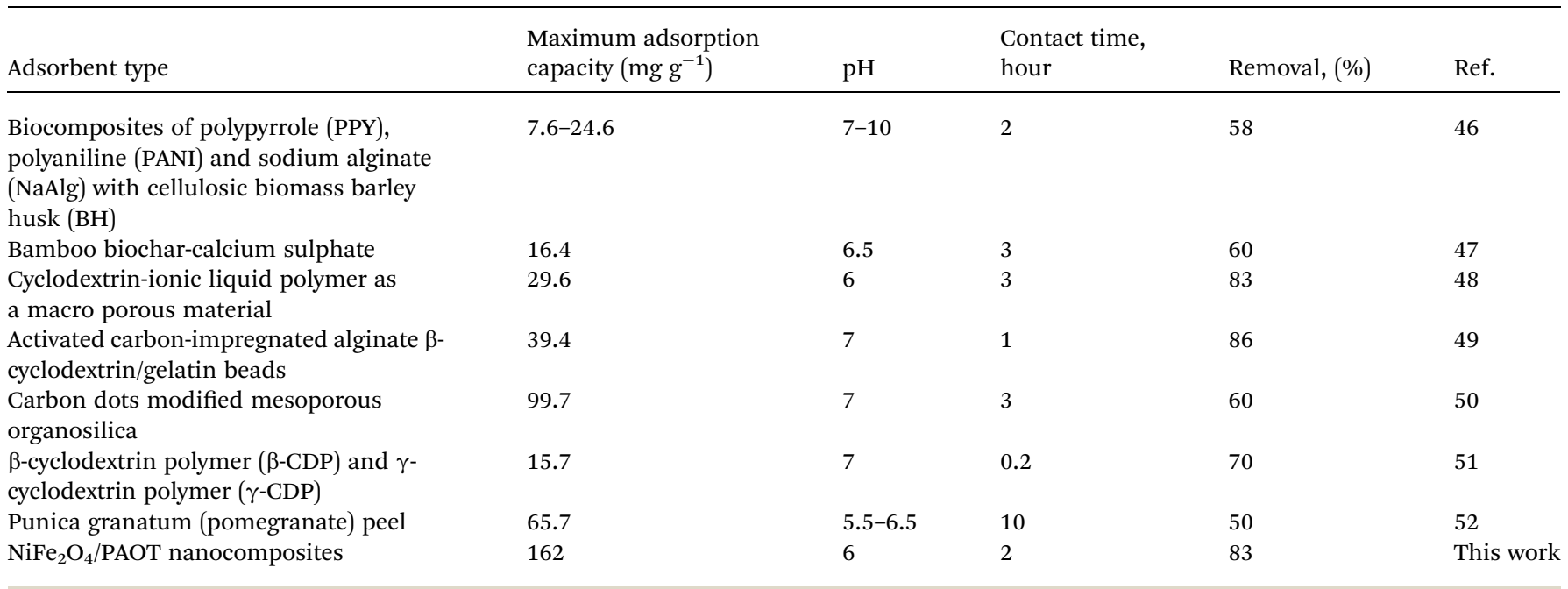

\section{Conclusions}

Nickel ferrite nanoparticles were synthesized, characterized, and used before and after modification with poly(aniline-co-otoluidine) to form $\mathrm{NiFe}_{2} \mathrm{O}_{4} / \mathrm{PAOT}$ nanocomposites. The composite is satisfactory used as adsorbent for the effective removal of 2,4-dichlorophenol (2,4-DCP) from aqueous solutions. The average sizes of the synthesized $\mathrm{NiFe}_{2} \mathrm{O}_{4}$ nanoparticles and $\mathrm{NiFe}_{2} \mathrm{O}_{4} / \mathrm{PAOT}$ nanocomposite are 12.3 and $16.7 \mathrm{~nm}$, respectively. Under optimized conditions, $\mathrm{NiFe}_{2} \mathrm{O}_{4} /$ PAOT nanocomposite efficiently adsorb and remove 2,4-DCP from aqueous solutions. At $\mathrm{pH}<6$, the removal efficiency and 
maximum adsorption capacity $\left(Q_{\mathrm{m}}\right)$ are $24 \%, 36 \mathrm{mg} \mathrm{g}^{-1}$ for $\mathrm{NiFe}_{2} \mathrm{O}_{4}$ nanoparticles and $83 \%, 162 \mathrm{mg} \mathrm{g}^{-1}$ for $\mathrm{NiFe}_{2} \mathrm{O}_{4} / \mathrm{PAOT}$ nanocomposite, respectively. This is probably due to the electrostatic attractions between positively changed atoms located in the copolymer chain and 2,4-DCP molecules. Non-covalent $\pi-\pi$ interactions between the aromatic ring of 2,4-DCP and aromatic rings of copolymer layer are also involved in the removal mechanism. Langmuir, Freundlich and RedlichPeterson isotherm models were applied to fit the experimental data and Redlich-Peterson model is the most appropriate model for the adsorption process and both adsorbents followed the second order model. $\mathrm{NiFe}_{2} \mathrm{O}_{4} / \mathrm{PAOT}$ nanocomposite is stable and easily removed from aqueous solution after treatment by an external magnetic field and recycled for reuse for at least 5 cycles without loss of removal efficiency.

\section{Author contributions}

The listed authors contributed to this work are described as follows: S. S. M. H and A. H. K. contributed to the concepts of the work, interpretation of the results and prepared the manuscript. The experimental part was conducted by M. A. F. Preparation of the manuscript and the revision before submission were conducted by A. H. K., S. S. M. H. and M. A. F. All authors have read and agreed to the published version of the manuscript.

\section{Conflicts of interest}

The authors declare that there are no conflicts of interest. All authors have approved the manuscript and agree with the submission to your esteemed journal.

\section{References}

1 W. Duan, F. Meng, H. Cui, Y. Lin, G. Wang and J. Wu, Ecotoxicol. Environ. Saf., 2018, 157, 441-456.

2 E. O. Igbinosa, E. E. Odjadjare, V. N. Chigor, I. H. Igbinosa, A. O. Emoghene, F. O. Ekhaise, N. O. Igiehon and O. G. Idemudia, Sci. World J., 2013, 2013, 1-12.

3 X. Li, M. Zhou, Y. Pan and L. Xu, Chem. Eng. J., 2017, 307, 1092-1104.

4 C. Zhang, M. Zhou, G. Ren, X. Yu, L. Ma, J. Yang and F. Yu, Water Res., 2015, 70, 414-424.

5 M. Ya, Y. Wu, Y. Li and X. Wang, Chemosphere, 2017, 170, 7582.

6 N. Aristov and A. Habekost, Chemosphere, 2010, 80, 113-115.

7 M. Al-Obaidi, C. Kara-Zaitri and I. M. Mujtaba, J. Water Proc. Eng., 2018, 22, 131-137.

8 O. Ayodele, J. Lim and B. Hameed, Appl. Catal., A, 2012, 413, 301-309.

9 M. Amini, M. Arami, N. M. Mahmoodi and A. Akbari, Desalination, 2011, 267, 107-113.

10 M. Abbasi and N. R. Asl, J. Hazard. Mater., 2008, 153, 942947.

11 H. B. Hadjltaief, A. Sdiri, W. Ltaief, P. Da Costa, M. E. Galvez and M. B. Zina, C. R. Chim., 2018, 21, 253-262.
12 L. Fan, Y. Zhou, W. Yang, G. Chen and F. Yang, Dyes Pigm., 2008, 76, 440-446.

13 N. Singh, G. Nagpal and S. Agrawal, Environ. Technol. Innovation, 2018, 11, 187-240.

14 I. Ali, M. Asim and T. A. Khan, J. Environ. Manage., 2012, 113, 170-183.

15 J.-G. Yu, X.-H. Zhao, H. Yang, X.-H. Chen, Q. Yang, L.-Y. Yu, J.-H. Jiang and X.-Q. Chen, Sci. Total Environ., 2014, 482, 241-251.

16 S. Karthikeyan, V. Gupta, R. Boopathy, A. Titus and G. Sekaran, J. Mol. Liq., 2012, 173, 153-163.

17 L. Yang, Z. Chen, D. Zhang, Y. Liu, Y. Han and J. Shen, Water Sci. Technol., 2011, 63, 45-50.

18 H. Wang, L. Pan, W. Deng, G. Yang and X. Liu, Polym. J., 2016, 48, 787-792.

19 X. Chen, L. Di, H. Yang and T. Xian, J. Ceram. Soc. Jpn., 2019, 127, 221-231.

20 S. Homaeigohar, Nanomaterials, 2020, 10, 295.

21 S. Homaeigohar, N. K. Botcha, E. Zarie and M. Elbahri, Nanomaterials, 2019, 9, 250.

22 S. Homaeigohar and M. Elbahri, Water, 2019, 11, 2.

23 A. H Kamel, A. A. Hassan, A. E.-G. E. Amr, H. H. El-Shalakany and M. A. Al-Omar, Nanomaterials, 2020, 10, 586.

24 A. Samadi, M. Xie, J. Li, H. Shon, C. Zheng and S. Zhao, Chem. Eng. J., 2021, 129425.

25 L. Hlekelele, N. E. Nomadolo, K. Z. Setshedi, L. E. Mofokeng, A. Chetty and V. P. Chauke, RSC Adv., 2019, 9, 14531-14543.

26 E. N. Zare, A. Motahari and M. Sillanpää, Environ. Res., 2018, 162, 173-195.

27 A. Nasar and F. Mashkoor, Environ. Sci. Pollut. Res., 2019, 26, 5333-5356.

28 K. Mylkie, P. Nowak, P. Rybczynski and M. Ziegler-Borowska, Materials, 2021, 14, 248.

29 D. Kumar, Synth. Met., 2000, 114, 369-372.

30 R. B. Baird, Standard Methods for the Examination of Water and Wastewater, 23rd, Water Environment Federation, American Public Health Association, American, 2017.

31 A. H. Kamel, Life Sci. J., 2013, 10, 1657-1664.

32 T. A. Osmari, R. Gallon, M. Schwaab, E. Barbosa-Coutinho, J. B. Severo Jr and J. C. Pinto, Adsorpt. Sci. Technol., 2013, 31, 433-458.

33 N. Ayawei, A. N. Ebelegi and D. Wankasi, J. Chem., 2017, 2017, 3039817.

34 S. Gunasekaran, G. Anbalagan and S. Pandi, J. Raman Spectrosc., 2006, 37, 892-899.

35 S. Joshi, M. Kumar, S. Chhoker, G. Srivastava, M. Jewariya and V. Singh, J. Mol. Struct., 2014, 1076, 55-62.

36 I. Kulszewicz-Bajer, A. Proń, J. Abramowicz, C. Jeandey, J.-L. Oddou and J. W. Sobczak, Chem. Mater., 1999, 11, 552-556.

37 A. Epstein, J. Ginder, F. Zuo, H.-S. Woo, D. Tanner, A. Richter, M. Angelopoulos, W.-S. Huang and A. MacDiarmid, Synth. Met., 1987, 21, 63-70.

38 S. Qu, J. Wang, J. Kong, P. Yang and G. Chen, Talanta, 2007, 71, 1096-1102.

39 S. S. Hassan, A. H. Kamel, A. A. Hassan, A. E.-G. E. Amr, H. A. El-Naby and E. A. Elsayed, Nanomaterials, 2020, 10, 254. 
40 M. Thommes, K. Kaneko, A. V. Neimark, J. P. Olivier, F. Rodriguez-Reinoso, J. Rouquerol and K. S. Sing, Pure Appl. Chem., 2015, 87, 1051-1069.

41 P. P. IUPAC, D. Everett, R. Haul, L. Moscou, R. Pierotti, J. Rouquerol and T. Siemieniewska, Chem, 1985, 57, 603.

42 J. De Boer, B. Lippens, B. Linsen, J. Broekhoff, A. Van den Heuvel and T. J. Osinga, J. Colloid Interface Sci., 1966, 21, 405-414.

43 J.-P. Wang, Y.-Z. Chen, H.-M. Feng, S.-J. Zhang and H.-Q. Yu, J. Colloid Interface Sci., 2007, 313, 80-85.

44 F. Brouers and T. J. Al-Musawi, J. Mol. Liq., 2015, 212, 46-51.

45 X. Zhang, H. Dai, H. Yan, W. Zou and D. Cremer, J. Am. Chem. Soc., 2016, 138, 4334-4337.
46 H. N. Bhatti, Z. Mahmood, A. Kausar, S. M. Yakout, O. H. Shair and M. Iqbal, Int. J. Biol. Macromol., 2020, 153, 146-157.

47 A. H. Alamin and L. Kaewsichan, Pol. J. Chem. Technol., 2016, 18, 59-67.

48 M. Raoov, S. Mohamad and M. R. Abas, J. Hazard. Mater., 2013, 263, 501-516.

49 I. H. Alsohaimi, M. El-Aassar, A. A. Elzain, M. S. Alshammari and A. S. Ali, J. Mater. Res. Technol., 2020, 9, 5144-5153.

50 L. Wang, C. Cheng, S. Tapas, J. Lei, M. Matsuoka, J. Zhang and F. Zhang, J. Mater. Chem. A, 2015, 3, 13357-13364.

51 N. Li, Z. Mei and S. Ding, J. Inclusion Phenom. Macrocyclic Chem., 2010, 68, 123-129.

52 A. Bhatnagar and A. Minocha, J. Hazard. Mater., 2009, 168, 1111-1117. 